\title{
Kajian Analisa Usaha Sale Pisang Gulung di UD. Putra Roti Banjarnegara
}

\author{
Business Analysis Study on Banana Roll Sale at UD. Putra Roti Banjarnegara
}

\author{
Magfira Shifa Amartasya', Dwi Ari Cahyani \\ ${ }^{1}$ Mahasiswa Program Studi Agroindustri, Politeknik Banjarnegara \\ ${ }^{2}$ Program Studi Agroindustri, Politeknik Banjarnegara
}

\begin{tabular}{l}
\hline \hline ARTICLE INFO \\
\hline Article history: \\
DOI: \\
$\underline{\text { 10.30595/pspfs.v2i.199 }}$ \\
Submitted: \\
July 29, 2021 \\
Accepted: \\
Sept 10, 2021 \\
Published: \\
Nov 10, 2021 \\
\hline
\end{tabular}

\section{Keywords:}

Banana Sale, Business Analysis, Profit

\begin{abstract}
Banana sale is an alternative food that is processed by drying. Traditionally, sale processing is done by drying, but some are smoked first with firewood, but this smoking makes the quality of banana sale less good. The business analysis study in this study was to determine the extent to which the banana roll business was profitable, to determine the profit and loss and sustainability of the business managed by UD Putra Roti Banjarnegara. This research was conducted at UD Putra Roti. The location was chosen because UD Putra Roti is one of the most popular food businesses in Banjarnegara district. The research was conducted in October - December 2020. The data collected in the study were primary data and secondary data. The data collected was then analyzed using data analysis. Data analysis methods used, namely: gross income, net income, depreciation of equipment, BEP, RC Ratio, BC Ratio and ROI. Processing of sale banana rolls at UD Putra Roti includes procurement of raw materials, sorting, slicing, arranging, drying, rolling dried bananas, cutting rolls, standing, making dough rolls, frying, draining, and packaging. The results of the analysis show that the sale of banana rolls processing business carried out at UD. Putra Roti is feasible to do with an RC ratio > 1, which is 1.39. BC Ratio of 0.39 and 39\% ROI The ROI obtained is 39\%, which means that each capital is Rp. 100, obtained a profit of Rp. 39.
\end{abstract}

This work is licensed under a Creative Commons Attribution 4.0 International License.

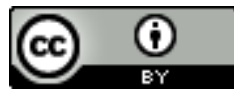

Corresponding Author:

Dwi Ari Cahyani

Program Studi Agroindustri, Politeknik Banjarnegara

Email: cahyanidwiari@gmail.com

\section{PENDAHULUAN}

Buah pisang adalah buah yang kaya akan manfaat karena pisang mengandung kandungan gula yang lengkap, yaitu glukosa, sukrosa dan fruktosa. Kandungan kalori pisang sekitar 90 kalori. Kandungan kalori tersebut termasuk tinggi untuk kategori buah-buahan. Tidak sedikit orang yang menyukai buah pisang mulai dari anak-anak, remaja dan orang dewasa bahkan para olahragawan banyak yang menyukai buah pisang sebagai pemulih stamina sehingga kebutuhan energi akan tergantikan setelah melakukan aktifitas olahraga (Adaninggar, 2013).

Permasalahan konsumsi pisang dalam bentuk segar, yaitu pisang mudah rusak dan cepat mengalami perubahan mutu setelah panen, karena memiliki kandungan air tinggi dan aktifitas proses metabolismenya meningkat setelah dipanen (Demeriel et all, 2003 dalam Histifarina et all, 2012). Diversifikasi olahan pisang dapat dilakukan untuk memperpanjang umur simpan pisang. UD Putra Roti yang di ketuai oleh ibu Sri Watini

Proceedings homepage: https://conferenceproceedings.ump.ac.id/index.php/pspfs/issue/view/9 
yang beralamat di desa Mertasari kecamatan Purwonegoro kabupaten Banjarnegara mengembangkan usaha sale gulung pisang sebagai salah satu diversifikasi olahan pisang.

UD. Putra Roti merupakan usaha kelompok yang memproduksi berbagai macam keripik, kue dan aneka tepung. Pada awal tahun 2010 pemilik UD. Putra Roti membuka usaha mandiri di rumahnya dengan menjual roti basah, roti kering, serta roti kue ulang tahun. pada tahun 2014 pemilik UD. Putra Roti ini mulai di lihat oleh angoota pengurus UPPKS (Usaha Peningkatan Pendapatan Keluarga Sejahtera) dan beliau diberi tugas untuk mengumpulkan teman dan tetangganya agar membentuk sebuah kelompok UPPKS di Desa Mertasari. Selanjutnya UD. Putra Roti ini di daftarkan menjadi usaha UMKM di Banjarnegara dan berkembang seiring berjalannya waktu, UD. Putra Roti merambah kepada pembuatan makanan ringan, kue kering dan keripik berinovasi herbal. Pemasaran yang di lakukan oleh pemilik UD. Putra Roti cukup luas ke berbagai kota hingga luar kota dan sekarang UMKM tersebut sudah mengikuti berbgai perlombaan dan menjuari beberapa lomba UMKM di tingakat Kecamatan dan Kabupaten.

Sale pisang merupakan makanan alternatif untuk menghindari pembusukan buah pisang yang diolah dengan cara pengeringan (Indradewi, 2016). Sale pisang memiliki rasa dan aroma yang khas, dengan indikator mutu berupa kekenyalan, ketahanan simpan, dan warna yang menarik (Badan Pengawasan Obat dan Makanan, 2019). Sale pisang yang warnanya kuning kecoklatan, mengkilat, dan memiliki rasa dengan warna yang disukai yaitu berwarna coklat, beraroma pisang dengan tekstur yang agak keras. Bila pengolahannya baik daya simpannya dapat bertahan lebih lama. Secara tradisional pengolahan sale dilakukan dengan cara dijemur akan tetapi ada juga yang diasapkan terlebih dahulu dengan kayu bakar, namun pengasapan ini membuat mutu sale pisang menjadi kurang baik sehingga jarang dilakukan (Marwati et all, 2017).

Penelitian tentang kajian analisa usaha sudah sangat banyak terdapat dalam jurnal - jurnal penelitian. Pada Penelitian ini kajian analisa usaha dilakukan untuk mengetahui sejauh mana tingkat kelayakan usaha sale gulung pisang yang di produksi di UD. Putra Roti Banjarnegara yang belum pernah dikaji sebelumnya. Kajian analisa usaha pada penelitian ini yaitu untuk mengetahuai sejauh mana usaha sale pisang gulung memberikan keuntungan, mengetahui rugi laba dan keberlanjutan dalam usaha yang dikelola oleh UD Putra Roti.

\section{METODE PENELITIAN}

Penelitian ini dilaksanakan di UD Putra Roti Banjarnegara. Pemilihan lokasi dikarenakan UD. Putra Roti merupakan salah satu usaha makanan yang sedang popular di Kabupaten Banjarnegara. Penelitian dilaksanakan pada bulan Oktober - Desember 2020. Data yang dikumpulkan pada penelitian ini adalah data primer dan data sekunder. Data primer diperoleh dari pengusaha meliputi: jumlah dan harga faktor produksi, jenis dan bahan baku, bahan penunjang, tenaga kerja, alat dan mesin yang digunakan serta data lain yang diperlukan. Data sekunder diperoleh dari laporan bulanan usaha yang meliputi: keadaan umum usaha, sejarah singkat usaha, ditambah juga dengan data lain yang menunjang penelitian ini baik dari instansi yang terkait maupun dari literatur lainnya. Data yang dikumpulkan kemudian dianalisis dengan menggunakan analisis data. Metode analisis data yang digunakan, yaitu: pendapatan kotor, pendapatan bersih, penyusutan peralatan, efisiensi usaha dan titik impas penerimaan.

\section{HASIL DAN PEMBAHASAN Pengolahan Sale Pisang Gulung}

Sale juga termasuk makanan alternatif yang banyak diproduksi dan memiliki kandungan gizi seperti, pati, gula, vitamin A dan C, kalium, kalsium, natrium dan magnesium serta mengandung serotonin yang aktif sebagai neurotransmitter untuk kecerdasan otak. Kandungan mineral yang unggul dalam buah pisang adalah kalium yakni berkisar $440 \mathrm{mg}$. Kalium bermanfaat untuk menjaga keseimbangan air dalam tubuh, kesehatan jantung, tekanan darah. (Ashokkumar et all, 2018).

Proses pengolahan sale pisang cukup memakan waktu yang lama di hitung mulai pra produksi hingga post produksi yang membutuhkan waktu sekitar 10 hari. Langkah pengolahan sale pisang adalah pengadaan bahan baku, sortasi buah pisang, pengirisan pisang, penataan pisang, penjemuran pisang, penggulungan pisang kering, memperkecil ukuran gulungan pisang, pendiaman gulungan pisang, pembuatan adonan gulungan pisang, penggorengan gulungan pisang, penirisan sale, dan pengemasan sale gulung.

Pengadaan buah pisang diperoleh dari pedagang pisang yang berada disekitar UD. Putra Roti. Pisang yang digunakan untuk produksi harus memenuhi standar yang ditetapkan oleh perusahaan. dengan kriteria pisang raja uter memiliki tingkat kematangan sekitar 40\%-50\% (tingkat kematangan untuk penyimpanan bahan baku), kulit buahnya tidak cacat, buah masih berwarna hijau/sedikit kekuningan, buah pisang masih keras, buahnya besar-besar, buah tidak terlalu melengkung.

Sortasi bahan baku adalah memilih buah pisang yang sudah masak, karena apabila bahan baku yang digunakan belum masak akan mengurangi cita rasa dari sale pisang tersebut. Kriteria buah pisang yang siap untuk diolah yaitu : kulit buah berwarna kuning, pisang memiliki tingkat kematangan sekitar 70\%-80\% (dengan cara menggoyangkan pisang dari bonggolnya ketika lepas pisang sudah bisa diolah), karena pisang yang 
memiliki tingkat kematangan $100 \%$, pada saat pengirisan pisang terjadi kesulitan dikarenakan pisang menjadi sangat lunak.

Pengirisan pisang dilakukan untuk membelah pisang menjadi beberapa bagian tipis tipis, cara pengirisan pisang ini adalah memanjang secara horizontal, biasanya satu pisang dapat di iris menjadi 9-12 bagian.Sehingga pisang menjadi mudah di jemur. Penataan pisang di nampan ayaman bambu di lakukan agar pisang menjadi mudah di gulung, dengan pola tata pada 4 lembar pisang di tata berjejer kemudian pada salah satu ujung pisang di beri irisan pisang yang terlalu tebal atau pisang yang salah pemotongan. Kegunaan dari peletakan irisan pisang di atas 4 lembaran pisang ini untuk perekat ke-empat lembar pisang tersebut. Penjemuran pisang masih mengandalkan panas sinar matahari, serta memerlukan waktu sekitar 3-4 hari ketika ketika cuaca sedang bagus atau panas terik, apabila cuaca tidak mendukung penjemuran dilakukan 4 hari lebih. Pisang yang sudah kering memiliki ciri: teksturnya menjadi sedikit keras, berubah warna menjadi sedikit kecoklatan, ketika di angkat tidak pisang sudah tidak lengket. Cara penjemuran ini mempunyai kapasitas yang tidak efektif dengan menggunakan sinar matahari, temperatur dan kelembaban yang tidak dapat dikontrol. Pengeringan dengan menggunakan alat pengering dapat meningkatkan mutu produk (Rita Khatir et all, 2011).

Proses penggulungan merupakan proses pembentukan lembaran pisang kering menjadi gulungan pisang. sehingga menjadikan sale ini berbeda dengan biasanya yang berbentuk lembaran pisang, proses penggulungan ini di bantu dengan stik gulung yang terbuat dari bambu kecil. dengan cara sale kering di lilitkan di atas stik kemudian putar searah jarum jam, memutarnya dengan sedikit penekan, kemudian ujung pisang kering di beri lem yang terbuat dari tepung $1 / 4 \mathrm{~kg}$ terigu dan $200 \mathrm{ml}$ air di campur menjadi adonan perekat adonan perekat ini tidak boleh encer harus kental. Setelah proses penggulungan dilakukan proses pengguntingan sale ini di lakukan setelah proses penggulungan. yang bertujuan untuk menseragamkan bentuk sale yang akan di goring, karena ketika tidak di gunting hasil sale menjadi panjang. Ukuran pemotongan gulungan pisang yaitu 1 gulungan kecil di potong menjadi 2 dan untuk gulungan pisang yang panjang di potong menjadi 3 bagian rata-rata panjang potongan ini gulungan sale yaitu sekitar $3 \mathrm{~cm}$. Proses selanjutnya yaitu proses pendiaman sale. Proses ini merupakan bagian terpenting karena menentukan cita rasa dari sale, karena pada proses ini gulungan pisang akan mengelurkan rasa manis dari pisang secara menyeluruh, Menurut (Tamrin et all., 2014), pisang merupakan buah klimaterik yaitu buah yang akan tetap melangsungkan proses kematangan meskipun telah di panen diikuti dengan proses kerusakan karena buah tetap melangsungkan prosees respirasi dan metabolisme. Perubahan warna pada gulungan pisang saat proses pendiaman berlangsung yaitu menjadi coklatan gelap. Proses pendiaman ini dilakukan selama 3-4 hari. Pendiaman ini terdapat dua cara: pertama pisang yang sudah di gulung di masukkan kedalam kardus kemudian tutup diberi isolasi dan kedua gulungan pisang yang sudah di gunting dimasukan ke dalam kardus kemudian tutup di beri isolasi atau di letakan di atas tampah kemudian tutup kembali dengan tampah. Proses pendiaman ini juga merupakan proses penyimpanan bahan baku sale secara tidak langsung.

Langkah selanjutnya yaitu pembuatan adonan pembungkus sale pisang. Pembuatan adonan sale digunakan untuk pembalut gulungan pisang yang sudah di potong, bahan-bahan yang di butuhkan yaitu tepung beras, tepung mocaf, tepung terigu, telur, vanili, garam, air dan minyak untuk menggoreng. Bahan adonan digunakan untuk penggorenan gulungan pisang sebanyak $10 \mathrm{~kg}$ pisang segar. Penambahan tepung mokaf dimaksudkan untuk menekan biaya tepung terigu yang digunakan. Menurut (Nuron et all, 2014) keunggulan dari tepung mocaf ini yaitu bahan baku yang tersedia cukup banyak dan harga singkong sebagai bahan baku relatif murah dibandingkan harga gandum sebagai bahan baku terigu. Setelah dibuat adoanan pembungkus sale selanjutnya dilakukan proses penggorengan setelah gulungan pisang sudah melalui proses pendiaman. Penggorengan gulungan pisang memerlukan minyak yang cukup panas, yaitu minyak sudah memdidih mengeluarkan uap. Penggorengan sale membutukan waktu sekitar 7 menit dalam sekali penggorengan. Setelah digoreng dilakukan proses penirisan. Penirisan yaitu membuang kadar minyak yang masih ada pada sale secara menyeluruh dari penggorengan. Proses penirisan dilakukan dengan menggunakan mesin spinner, proses ini menjadikan sale lebih kering dari minyak, sehingga membuat sale memiliki daya simpan yang lebih lama karena pengurangan kadar minyak serta sale menjadi lebih reyah ketika di makan. Sale pisang gulung selanjutnya dikemas menggunakan plastik kemudian di kemas lagi dengan pengemasan sekunder menggunakan kardus berlabel, plastik PE ber-standing pouch, dan pengemasan secara curah.

\section{Analisa Usaha}

Analisa kelayakan usaha dalam bidang agribisnis atau disebut juga feasibility study adalah kegiatan untuk menilai sejauh mana manfat yang dapat diperoleh dalam melaksanakan suatu kegiatan usaha. Hasil analisis ini digunakan sebagai bahan pertimbangan dalam mengambil keputusan, apakah menerima atau menolak dari suatu gagasan usaha. Pengertian layak dalam penelitian ini adalah kemungkinan dari gagasan suatu usaha yang akan dilaksanakan dapat memberikan manfaat dalam arti finansial maupun sosial benefit ( Sarno, 2012). Analisa usaha yaitu proses menganalisis pengeluaran pada setiap produk yang dihasilkan dan meninjau layak tidaknya suatu usaha yang dijalankan. Biaya produksi adalah semua pengeluaran ekonomis yang harus dikeluarkan untuk memproduksi suatu barang. Berikut rumus untuk menghitung biaya produksi (Soekartawi, 2006). 
$\mathrm{TC}=\mathrm{TFC}+\mathrm{TVC}$

Keterangan:

$\mathrm{TC}=$ Total biaya dari usaha home industri kerupuk opak (Rp)

$\mathrm{TFC}=$ Total biaya tetap (Rp)

TVC = Total biaya variabel(Rp)

Biaya Tetap Biaya tetap adalah biaya yang jumlahnya tidak berpengaruh oleh perkembangan jumlah produksi atau penjualan dalam satu tahun. Biaya tetap merupakan biaya yang dikeluarkan oleh industri yang penggunaannya tidak habis dalam satu masa produksi (Soekartawi: 2009). Besar kecilnya biaya produksi tersebt tidak dipengaruhi oleh banyaknya produksi yang dihasilkanSedangkan biaya penyusutan adalah metode pengalokasikanbiaya perolehan asset tetap untuk secara sistematis mengurangi nilai asset selama masa manfaat asset (Martani, 2014).

Tabel 1. Biaya Penyusutan

\begin{tabular}{|c|c|c|c|c|c|}
\hline No. & Nama Barang & Harga Beli & $\begin{array}{c}\text { Harga Setelah } \\
\text { Beli }\end{array}$ & $\begin{array}{c}\text { Nilai } \\
\text { Ekonomis }\end{array}$ & $\begin{array}{c}\text { Biaya } \\
\text { Penyusutan } \\
\end{array}$ \\
\hline 1 & Pisau & Rp.6.000 & Rp.2.000 & 60 bulan & Rp.66,- \\
\hline 2 & Tampah & Rp.15.000 & Rp.5.000 & 12 bulan & Rp.833,- \\
\hline 3 & Widik & Rp.20.000 & Rp.5.000 & 12 bulan & Rp.1.250,- \\
\hline 4 & Stik penggulung & Rp.2000 & Rp.1.000 & 12 bulan & Rp.83,- \\
\hline 5 & Kompor gas & Rp.250.000 & Rp.150.000 & 72 bulan & Rp.1.900,- \\
\hline 6 & Wajan & Rp.50.000 & Rp.20.000 & 12 bulan & Rp.2.500,- \\
\hline 7 & Spatula & Rp.5.000 & Rp.2.000 & 12 bulan & Rp.250,- \\
\hline 8 & Expired date & Rp.75.000 & Rp.30.000 & 60 bulan & Rp.750,- \\
\hline 9 & Saringan & Rp.15.000 & Rp.5.000 & 12 bulan & Rp.833,- \\
\hline 10 & Penjepit & Rp.10.000 & Rp.2.000 & 12 bulan & Rp.666,- \\
\hline 11 & Baskom & Rp.30.000 & Rp.10.000 & 12 bulan & Rp.1.666,- \\
\hline 12 & Timbangan & Rp.380.000 & Rp.120.000 & 60 bulan & Rp.4.300,- \\
\hline 13 & Mesin spinner & Rp.2.300.000 & Rp.1.000.000 & 120 bulan & Rp.10.833,- \\
\hline 14 & Hand sealer & Rp.175.000 & Rp.75.000 & 36 bulan & Rp.2.777,- \\
\hline 15 & Gunting & Rp.10.000 & Rp.5.000 & 12 bulan & Rp.416,- \\
\hline \multicolumn{5}{|c|}{ Total } & Rp.29.123 \\
\hline
\end{tabular}

Sumber: Data diolah, 2021.

Komponen biaya tetap untuk 1 bulan produksi

a. Air dan listrik = Rp.375.000,-

b. tenaga kerja $=$ Rp. $600.000 \times 3$ $=1.800 .000$,-

Total biaya tetap untuk 1 bulan produksi $=$ Rp.2.175.000,- + Rp.29.123,-

\section{Biaya Variabel}

$$
=\text { Rp. } 2.204 .123
$$

Biaya variabel adalah biaya yang besar kecilnya selaras dengan perkembangan produksi atau penjualan setiap tahun (Nurmalina dan Sarianti 2012).

Table 2. Biaya Variabel

\begin{tabular}{|c|c|c|c|c|c|}
\hline No. & Nama Barang & Satuan & $\begin{array}{l}\text { Kebutuhan per } \\
\text { bulan }\end{array}$ & Harga satuan & Harga per bulan \\
\hline 1 & Pisang & $\mathrm{Kg}$ & 1.500 & Rp.4000 & Rp.6.000.000 \\
\hline 2 & Tepung Beras & $\mathrm{Kg}$ & 30 & Rp.10.000 & Rp.300.000 \\
\hline 3 & Tepung Mocaf & $\mathrm{Kg}$ & 7.5 & Rp.11.000 & Rp.82.500 \\
\hline 4 & Tepung Terigu & $\mathrm{Kg}$ & 7.5 & Rp.10.000 & Rp.75.000 \\
\hline 5 & Telur & Butir & 30 & RP.1.000 & Rp.33.000 \\
\hline 6 & Garam & Bungkus & 3 & Rp.5.000 & Rp.15.000 \\
\hline 7 & Minyak Goreng & Liter & 150 & Rp.10.000 & Rp.1.500.000 \\
\hline 8 & Kemasan + Label & Lembar & 400 & Rp.1.200 & Rp.480.000 \\
\hline 9 & Gas & $\mathrm{Kg}$ & 30 & Rp.20.000 & Rp.600.000 \\
\hline 10 & Vanili & pcs & 30 & Rp.500 & Rp. 15.000 \\
\hline \multicolumn{5}{|c|}{ Total } & Rp.9.100.500 \\
\hline
\end{tabular}

Sumber: Data diolah, 2021. 


\section{Biaya Total Satu Bulan}

Biaya produksi adalah semua pengeluaran yang dilakukan perusahaan untuk memproduksi barang/jasa (Susanto 2010). Biaya produksi terbagi atas biaya tetap (fixed cost) yaitu biaya produksi yang besarnya tidak berubah atau tidak dipengaruhi oleh volume produksi barang/jasa dan biaya variabel (variable cost) yaitu biaya produksi yang besarnya berubah-ubah sesuai dengan jumlah produksinya. Biaya total (total cost) adalah jumlah keseluruhan biaya yang dikeluarkan perusahaan untuk memproduksi barang/jasa.

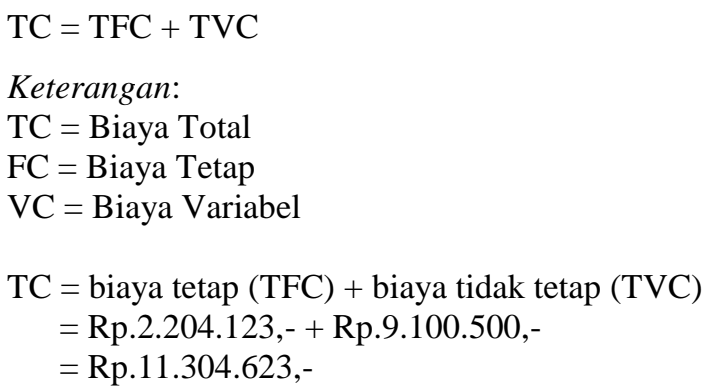

\section{Harga Pokok Produksi}

Dari 1 bulan produksi diperoleh 400 produk, maka untuk menentukan harga pokok produk dapat dihitung sebagai berikut :

$$
\begin{aligned}
\mathrm{HPP} & =\frac{\mathrm{TC}}{\mathrm{Q}} \\
& =\frac{\text { Rp. } 11.304 .623}{400}=\text { Rp. } 28.261
\end{aligned}
$$

\section{Harga Jual Produk}

Dengan menggunakan asumsi keuntungan 40\% maka, ditentukan harga jual produk sebagai berikut :

$$
\begin{aligned}
& =\frac{40}{100} \times 28.261 \\
& =\text { Rp. } 11.304,- \\
& =\text { HPP + 40\% } \\
& =\text { Rp. } 28.261,-+ \text { Rp. } 11.304,- \\
& =\text { Rp. } 39.565-/ \text { produk }
\end{aligned}
$$

\section{Analisa Keuntungan}

a. pendapatan/omset $=$ Harga Jual $\times$ jumlah produk

$$
\begin{aligned}
& =\text { Rp. } 39.565,-\times 400 \\
& =\text { Rp.15.826.000 }
\end{aligned}
$$

b. keuntungan bersih $=$ Pendapatan - Total biaya

$$
\begin{aligned}
& =\text { Rp. 15.826.000 - Rp.11.304.623.- } \\
& =\text { Rp.4.521.377,-- }
\end{aligned}
$$

\section{BEP (Break event Point)}

Break event point (BEP) merupakan kondisi dimana suatu usaha tidak megahasilkan keuntungan ataupun kerugian Analisis break event point, yaitu suatu alat analisis yang dapat digunakan untuk mengetahui hubungan antar variabel di dalam kegiatan perusahaan seperti, luas produksi atau tingkat produksi yang dilaksanakan, biaya yang dikeluarkan, serta pendapatan yang diterima perusahaan dari kegiatannya. BEP produksi merupakan total biaya dibagi dengan harga jual (Nasarudin 2013). BEP dapat tercapai apabila jumlah pendapatan sama dengan jumlah biaya produksi atau keuntungan sama dengan nol. Rumus yang digunakan untuk mengetahui besarnya BEP (Mahyudin, 2008). 


$$
\begin{aligned}
\text { a. BEP Harga } & =\frac{\mathrm{FC}}{1-\frac{\mathrm{VC}}{\text { Omset }}} \\
& =\frac{2.204 .123}{1-\frac{9.100 .500}{15.826 .000}} \\
& =\frac{2.204 .123}{5,71} \\
& =5.125 .867 \\
\text { b. BEP unit } & =\frac{\mathrm{FC}}{\mathrm{P}-\frac{\mathrm{VC}}{\mathrm{Q}}} \\
& =\frac{2.204 .123}{39.565-\frac{9.100 .500}{400}} \\
& =\frac{2.204 .123}{16.813} \\
& =131 \text { unit }
\end{aligned}
$$

\section{Revenue Cost Ratio}

Revenue Cost Ratio adalah suatu pengujian analisa kelayakan dengan perbandingan antara total pendapatan dengan total biaya yang dikeluarkan. R/C (Revenue Cost Ratio) diketahui dengan cara pembagian antara penerimaan dengan biaya total. Kriteria yang digunakan dalam analisis ini adalah apabila nilai $\mathrm{R} / \mathrm{C}>1$ maka usaha tersebut dikatakan untung dan layak untuk diusahakan, karena besarnya pendapatan lebih besar dari besarnya biaya yang dikeluarkan, dan sebaliknya (Mahyudin, 2008). Menurut Sajari (2017), yang dimaksud dengan Benefit/Cost (B/C) ratio merupakan suatu analisi yang memberikan suatu gambaran dalam memilih atau tidak memilih spesifikasi dari suatu investasi. Perhitungan hasil analisis pendapatan dengan biaya (R/C) dapat dilihat sebagai berikut:

$$
\begin{aligned}
\text { RC/Ratio } & =\frac{\text { Omset }}{\mathrm{TC}} \\
& =\frac{15.826 .000}{11.304 .623} \\
& =1,39 \\
\text { BC/Ratio } & =\frac{\text { laba }}{\mathrm{TC}} \\
& =\frac{4.521 .377}{11.304 .623} \\
& =0,39
\end{aligned}
$$

Berdasarakan hasil perhitungan diatas dapat diketahui bagwa RC ratio sebesar 1,39 yang berarti bahwa usaha sale pisang gulung di UD Putra Roti menguntungkan dan layak untuk dikembangan dimana setiap pengeluaran Rp 100 akan pendapatkan pemasukan sebesar Rp 139. Perhitungan BC Ratio yang didapatkan dari perhitungan sebesar 0,39 yang berarti bahwa dalam usaha pengolahan sale pisang gulung artinya bahwa setiap biaya yang dikeluarkan sebesar Rp 100 akan menghasilkan keuntungan Rp 39 dan layak untuk dikembangkan. 


\section{Return On Investment (ROI)}

Return on Investment (ROI) adalah salah satu bentuk dari rasio profitabilitas yang dimaksudkan untuk mengukur kemampuan perusahaan dengan keseluruhan dana yang ditanamkan dalam aktiva yang digunakan untuk operasinya perusahaan untuk menghasilkan keuntungan.

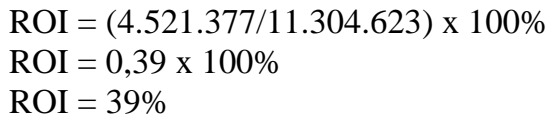

Berdasarkan perbandingan laba dan modal produksi diperoleh nilai ROI sebesar 39\%, yang berarti bahwa besarnya keuntungan yang diperoleh dibandingkan investasi (ROI) besarnya keuntungan yang diperoleh dibandingkan dengan investasi yang ditanamkan adalah baik, artinya setiap modal sebesar Rp. 100, diperoleh keuntungan sebesar Rp.39.

\section{KESIMPULAN}

Dari aspek finansial produk sale memiliki cukup menguntungkan karena memiliki keuntungan Rp.4.521.377 perbulan dengan total biaya Rp.11.304.623 perbulan. BEP (Break Event Point) atau titik impas yang didapat untuk harga adalah Rp.5.125.867,- perbulan dan titik impas produk adalah 131 unit per-bulan. Serta didapatkan R/C ratio > 1 yang menandakan bahwa analisa usaha yang diperhitungkan pada usaha pengolahan sale gulung pisang di UD Putra Roti Banjarnegara layak untuk dijalankan. Perhitungan BC Ratio yang didapatkan dari perhitungan sebesar 0,39 yang berarti bahwa dalam usaha pengolahan sale pisang gulung artinya bahwa setiap biaya yang dikeluarkan sebesar Rp 100 akan menghasilkan keuntungan Rp.39. ROI yang diperoleh sebesar 39\% artinya setiap modal sebesar Rp.100, diperoleh keuntungan sebesar Rp.39.

\section{UCAPAN TERIMA KASIH}

Pada kesempatan ini kami mengucapkan banyak terimakasih kepada ibu Sri Watini beserta seluruh karyawan UD. Putra Roti desa Mertasari Banjarnegara dan seluruh pihak yang terlibat dalam penelitian ini.

\section{DAFTAR PUSTAKA}

Adaninggar, E.S., Anggraeni, M., Yulianti, N. 2013. Keripik Pisang Rasa Dua. Usulan Program Kreativitas Mahasiswa. Universitas Dian Nuswantoro. Semarang

Amanu, Febri Nuron; Wahono Hadi Susanto. 2014. Pembuatan Tepung mocaf Di Madura (Kajian Varietas Dan Lokasi Penanaman) Terhadap Mutu Dan Rendemen. Pembuatan Tepung Mocaf DI Madura Amanu, Dkk Jurnal Pangan Dan Agroindustri Vol. 2 No. 3 P. 161- 169, Juli 2014.

Ashokkumar, K., Sivakumar, p., Elayabalan, S., Shobana, V. G,.\& Pandiyan, M. (2018). Nutritional Value of Cultivars of Banana (Musa Spp.) and its Future Prospects. Journal of Pharmacognosy and Phytochemistry, 7(3), 2972-2977.

Dewi Martani. 2014. Akuntansi Keuangan Menengah Berbasis PSAK. Jakarta: Salemba Empat.

Histifarina, D., Adetiya Rachman, Didit Rahadian, dan Sukmaya. 2012. Teknologi pengeolahan tepung dari berbagai jenis pisang menggunakan cara pengeringan matahari dan mesin pengering. Agrin Vol. 16, No.2, Oktober 2012 ISSN: 1410-0029.

Indradewi, F.(2016). Pengaruh Teknik Pengeringan Terhadap Kadar Gizi dan Mutu Organoleptik Sale Pisang (Musa paradisiaca L.) Fery Indradewi A, 4(2), hal : 58-65.

Khatir R., Ratna.,\& Wardani. (2011) Karakteristik Pengeringan Tepung Beras Menggunakan Alat Pengering Tipe Rak. Jurnal Ilmiah Pendidikan Biologi, Biologi Edukasi. Vol. 3, Nomor 2, 1-4.

Marwati, M., Yuliani, Y., Andriyani, Y., \& Mentari, M. (2017) Pengaruh Suhu Dan Lama Pengeringan Terhadap Sifat Kimia Dan Organoleptik Sale Pisang Kapas (Musa comiculata). Jurnal Kimia Mulawarman, 15(1), 22-24.

Nasarudin, I. 2013. Analisis Kelayakan Ekonomi Dan Keuangan Usaha Ikan Lele Asap Di Pekanbaru. Jurnal Etikonomi Vol. 12 No. 2 Oktober 2013.

Sajari Ibnu, Elfiana, Martina. 2017. Analisis KelayakanUsaha Keripik Pada UD Mawar Di Gampong Batee Ie Like Kecamatan Samalanga Kabupaten Bireuen. Jurnal S. Pertanian 1 (2) : 116 - 124 (2017) 116.

Sarno, 2012. Manajemen Agribisnis Teori Dan Aplikasi. Banjarnegara. Sukses Makmur Press. 
Soekartawi. 2006. Analisis Usaha Tani. Jakarta: UI Press.

Soekartawi. 2009. Agribisnis. Teori dan Aplikasinya. Rajawali Pers Universitas Brawijaya. Jakarta.

Suratiyah, K. 2015. Ilmu Usahatani. Penebar Swadaya. Jakarta. 